\title{
Impact of anoxia and sulfide on the viability of eggs of three planktonic copepods
}

\author{
N. H. Marcus*, R. V. Lutz, J. P. Chanton \\ Department of Oceanography, Florida State University, Tallahassee, Florida 32306, USA
}

\begin{abstract}
Eggs of 3 calanoid copepods Acartia tonsa, Centropages hamatus and Labidocera aestiva were exposed to either anoxia or anoxia/sulfide. Mean sulfide concentrations ranged from 283 to $352 \mathrm{M}$. Viability, determined at 4 d intervals for $32 \mathrm{~d}$ and judged as hatching success under normoxia was variable, but generally declined with increasing time of exposure. Values for hatching success were transformed to probits to determine the median lethal times of exposure to anoxia and anoxia/sulfide and $95 \%$ confidence limits. We observed no significant difference in the mortality of eggs exposed to anoxia/sulfide compared to anoxia alone and suggest that eggs switch to anaerobic metabolism when exposed to anoxia.
\end{abstract}

KEY WORDS: Copepods - Resting eggs - Anoxia - Sulfide

Eggs of planktonic copepods occur in coastal marine sediments (reviewed by Marcus 1996). The greatest numbers (e.g. $10^{6} \mathrm{~m}^{-2}$ ) occur in shallow (<20 m) muddy environments, e.g. estuaries. The sea bed in these areas is generally anoxic a few millimeters below the water sediment interface (Revsbech et al. 1980a, b) and often sulfidic (Theede et al. 1969, Fenchel \& Reidl 1970). Sulfide concentrations in sediment pore water range from a few micromolar to several hundred micromolar (see Bagarinao 1992). These levels are toxic to most aerobic organisms (National Research Council 1979).

Several studies (Uye \& Fleminger 1976, Ban \& Minoda 1992, Lutz et al. 1992, Marcus et al. 1994) indicate that copepod eggs can survive anoxia for days to weeks and in some cases years, but only 1 study has considered the impact of sulfide on copepod eggs. Uye et al (1985) reported low numbers of Acartia erythreae, $A$. pacifica, and $A$. clausi at stations in Fukuyama Harbor, Japan, and suggested the polluted sediments which smelled of hydrogen sulfide contributed to increased

·E-mail:marcus@ocean.fsu.edu egg mortality and thus reduced population densities. In this study we compared the impact of anoxia and anoxia/sulfide on the viability of eggs of 3 copepods, Acartia tonsa (Dana), Centropages hamatus (Lilljeborg), and Labidocera aestiva (Wheeler). The eggs of these species are common in the sea beds of many coastal areas.

Methods. Acartia tonsa, Labidocera aestiva, and Centropages hamatus were collected with a $243 \mu \mathrm{m}$ mesh plankton net from inshore waters near Turkey Point, Florida, USA $\left(29^{\circ} 51^{\prime} \mathrm{N}, 84^{\circ} 31^{\prime} \mathrm{W}\right)$, between June 1993 and August 1994. Sea-surface temperature and salinity were measured with a thermometer and refractometer (Reichert 0-30) respectively.

The plankton were transported to our laboratory, sub-samples were anaesthetized with MS-222 (Sigma Chemical, St. Louis, MO, USA), and sorted within $2 \mathrm{~h}$ of collection. Adults of the test species were transferred into 21 beakers containing filtered (glass-fiber, Gelman Type A/E; salinity $30 \%$ ) seawater, and a mixture of the dinoflagellates Scrippsiella trochoidea (clone Peri), Gymnodinium nelsoni (clone GSBL), and Prorocentrum micans (clone Proro) as food. The beakers were placed into incubators in the late afternoon for 10 to $19 \mathrm{~h}$, with the lights set to go on and off at 07:00 and 19:00 h respectively and constant temperatures of $20^{\circ} \mathrm{C}$ for Acartia tonsa, $15^{\circ} \mathrm{C}$ for Centropages hamatus, and $25^{\circ} \mathrm{C}$ for Labidocera aestiva. These temperatures are representative of conditions typically encountered by each species in the northeastern Gulf of Mexico, though not necessarily representative of field conditions at the times copepods were collected (Table 1).

Eggs produced during this incubation period were separated from the adults, by pouring the contents of the beakers through nested Nitex sieves, and then discarded. The sieve with the adults was rinsed with filtered seawater to remove any remaining eggs, the 
Table 1. Acartia tonsa, Centropages hamatus, and Labidocera aestiva. Dates and field conditions at the time of collection, and sulfide concentrations $( \pm 1 S D$ ) in the treatment vials

\begin{tabular}{|cccc|}
\hline Date & $\begin{array}{c}\text { Temp. } \\
\left({ }^{\circ} \mathrm{C}\right)\end{array}$ & $\begin{array}{c}\text { Salinity } \\
(\%)\end{array}$ & Sulfide (M) \\
\hline Acartia tonsa & & & \\
$\quad$ 23 Jun 1993 & 29.0 & 32 & $293.00 \pm 20.19$ \\
13 Jul 1994 & 29.0 & 29 & $297.49 \pm 29.69$ \\
Centropages hamatus & & & \\
$\quad$ 3 Jan 1994 & 12.5 & 30 & $337.61 \pm 36.77$ \\
31 Jan 1994 & 11.5 & 28 & $352.22 \pm 22.14$ \\
$\begin{array}{l}\text { Labidocera aestiva } \\
\text { 26 Jul 1993 }\end{array}$ & 30.0 & 32 & $282.89 \pm 47.44$ \\
8 Aug 1994 & 28.0 & 27 & $318.34 \pm 44.15$ \\
\hline
\end{tabular}

adults were returned to the beaker, given fresh food, and placed back in the incubator for $2 \mathrm{~h}$. Newly spawned eggs were collected as described above and within $1.5 \mathrm{~h}$ of collection were used to set-up the experiments described below.

Each experiment consisted of 2 sets of twenty-four $60 \mathrm{ml}$ hypo-vials (Pierce Chemical, Rockford, IL, USA): 1 set for exposure to anoxia and 1 set for exposure to anoxia/sulfide (hereafter referred to as sulfide). Each experiment also included 3 normoxic control vials to determine initial egg viability.

Eggs were transferred to each vial, the vial was capped with a rubber septum (Bellco, Vineland, NJ, USA, Size No. 20 rubber stoppers), and the contents were deoxygenated by gently bubbling with helium gas via a spinal needle inserted through the septum. Anoxic and control vials contained $25 \mathrm{ml}$ filtered seawater and $5 \mathrm{ml} 0.05 \mathrm{M}$ Tris ( $\mathrm{pH} 7.9$ to 8.1) diluted 1:5 with $20 \%$ salt solution (deionized water $+\mathrm{NaCl}$ ). Sulfide vials contained $25 \mathrm{ml}$ filtered seawater Sulfide was added later (see below). An additional needle was inserted into the headspace of each vial as a vent. After the vials had bubbled for $30 \mathrm{~min}$, the spinal needle was pulled from the seawater into the headspace, the vent needle was removed, and the contents of the vial were then pressurized with helium. After pressurization was complete, the spinal needle was removed. Pressurization was required for the gas chromatographic determination of oxygen. Following bubbling and pressurization, control vials were immediately injected with $120 \mathrm{ml}$ of air to yield normoxic concentrations and then re-pressurized with air. The anoxic vials received no further treatment after bubbling and initial pressurization. For the sulfide treatment, $5 \mathrm{ml}$ of Tris-buffered sulfide solution were injected into each vial after the spinal needle was pulled into the headspace.

The sulfide solution was prepared in a volumetric flask containing salt solution $(20 \%)$. This flask along with a flask containing $0.05 \mathrm{M}$ Tris buffer and another flask containing additional salt solution were bubbled for 45 min with nitrogen to deoxygenate the solutions. After the flasks were bubbled, crystals of sodium sulfide, washed free of oxidation products and wiped dry with KIMWIPES, were weighed, and $0.3 \mathrm{~g}$ were added to the volumetric flask containing the salt solution. The volume was adjusted by adding anoxic salt solution from the other flask. A Tris buffer sulfide solution was prepared as 5 parts sulfide solution and 1 part de-oxygenated Tris buffer solution.

Vials were stored in incubators at constant temperature $\left(15,20\right.$, and $25^{\circ} \mathrm{C}$ for Centropages hamatus, Acartia tonsa, and Labidocera aestiva respectively). The control vials were processed after at least $3 \mathrm{~d}$ of incubation. Three replicate vials from each of the anoxia and sulfide sets were processed every $4 \mathrm{~d}$ for $32 \mathrm{~d}$. In 1 experiment with $A$. tonsa (collection date 23 June 1993) vials were processed on Day 13 rather than Day 12 and Day 21 rather than Day 20. Gases in the headspace of the control and anoxic treatment vials were analyzed for oxygen concentration using the gas chromatographic headspace equilibration method (Lutz et al. 1992). Some vials were no longer pressurized at the end of the incubation period, which meant that the oxygen concentration could not be determined; these vials were not examined further. After oxygen determination the contents of the control and the anoxic treatment vials were poured through a $48 \mu \mathrm{m}$ sieve into a beaker, and the $\mathrm{pH}$ of the seawater was measured with an Orion ionalyzer (model 601a). The material on the sieve was rinsed with filtered seawater, transferred into a glass dish, observed with a dissecting microscope and unhatched eggs were transferred to wells of a plastic tray containing normoxic filtered seawater. The eggs were counted and returned to the incubator at the appropriate temperature for that species. Since eggs do not hatch under anoxia the viability of eggs exposed to anoxia was determined after transferring them to normoxic conditions. Viability, i.e. hatching success (indicated by the number of empty egg envelopes), was monitored at least every fifth day and final hatch percentage was determined after incubating the eggs at the species-specific temperature for at least $8 d$

Sulfide concentrations were determined in the sulfide vials using the Cline method (Cline 1969). In a few experiments sulfide was not detected in some of the vials; these vials were not examined further The vials in which sulfide was detected were processed as described above to determine egg viability.

The final hatch percentage for each vial was arcsine transformed. Means and standard deviations were calculated from the transformed values for each incubation period for each collection date. These values were then transformed back to a percentage value. Egg mor- 
tality values were also transformed to probits (Finney 1952) to determine the median lethal time of exposure to anoxia and sulfide and $95 \%$ confidence limits.

Results. We conducted 2 experiments with eggs of each species. Surface water temperature and salinity at the time of the collections are shown in Table 1.

The experimental procedure yielded oxygen concentrations in the control vials ranging from 4.67 to $9.77 \mathrm{ml} \mathrm{l}^{-1}$. The initial and final oxygen concentrations in most of the 128 treatment vials were $<0.01$ and $0.00 \mathrm{ml}^{-1}$ respectively. In 5 vials the final oxygen concentration ranged from 0.01 to $0.03 \mathrm{ml} \mathrm{l}^{-1}$. Of the 35 vials processed on Days 4 and 8,25 had initial and final oxygen concentrations of 0.01 and $0.00 \mathrm{ml} \mathrm{l}^{-1}$ respectively, suggesting that the oxygen concentration dropped to an undetectable amount within $4 \mathrm{~d}$ in most of the vials that contained trace amounts of oxygen initially.

The mean concentration $( \pm S D$ ) of sulfide detected in the vials of the different experiments ranged from $282.89 \pm 47.44$ to $352.22 \pm 22.14 \mu \mathrm{M}$ (Table 1 ). Sulfide concentrations did not differ among treatment vials in any consistent manner during an experiment. In some experiments there was a positive relationship between sulfide concentration and time of incubation, in others there was a negative relationship or no change. This variation may have been due to oxidation of sulfide in those vials which contained trace amounts of oxygen and/or slight differences in the amount of sulfide used to prepare the stock solution in the different experiments.

The protocol called for the initial introduction of 30 eggs into each vial. Based upon the number of eggs recovered from each vial, this value actually ranged from 10 to 91 (mean $\pm S D, 26.96 \pm 7.52$ ). The viability of eggs in the control vials was generally $\geq 84 \%$ with the exception of the experiments with Labidocera aestiva (Fig. 1, Day 0; 8 August 1994). Viability was variable in the anoxic and sulfide vials, but generally declined with time of exposure. The significance level of the chisquared statistic calculated by the probit analysis was small in most experiments. Therefore a heterogeneity correction was automatically applied to the estimated variances (SPSS 1993) to calculate the median lethal times of exposure and $95 \%$ confidence limits (Table 2). There was little if any systematic impact of sulfide on hatching success beyond that associated with anoxia. The $95 \%$ confidence limits for the anoxia and sulfide treatments overlapped for the experiments with Acartia tonsa and Centropages hamatus. The 2 experiments with eggs of $L$. aestiva yielded quite different median lethal time of exposure values, $>32 \mathrm{~d}$ and $<5 \mathrm{~d}$.

Discussion. The eggs used in all of the experiments were subitaneous as evidenced by the generally high hatching success of the controls. The unhatched eggs
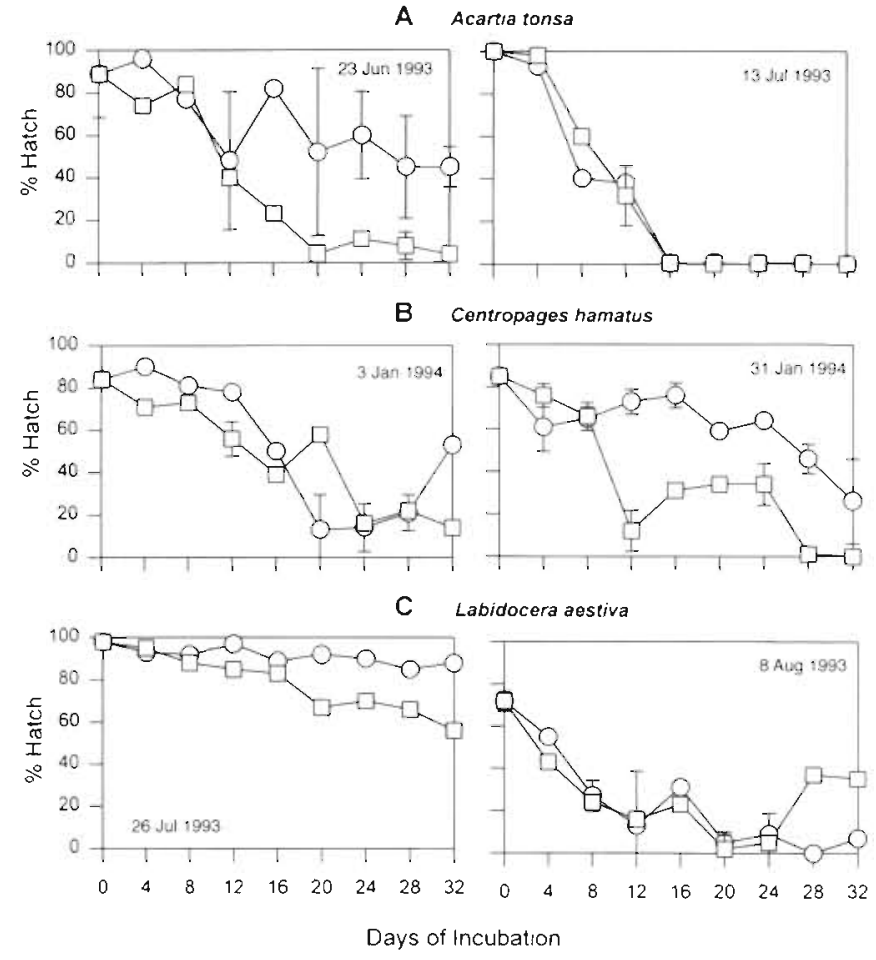

Fig. 1. Mean $( \pm S D)$ hatching success of eggs obtained from (A) Acartia tonsa collected in June 1993 and July 1994; (B) Centropages hamatus in January 1994; and (C) Labidocera destiva in July 1993 and August 1994. Eggs were exposed to anoxia (-O) and sulfide (- - - $)$. Where error bars are not obvious they are small and within the perimeter of the symbol

Table 2. Median lethal times of exposure and $95 \%$ confidence limits for each experiment. (-) indicates that confidence limits were not generated by the SPSS (1993) program

\begin{tabular}{|c|c|c|c|}
\hline \multirow[t]{2}{*}{ Experiment } & \multirow{2}{*}{$\begin{array}{l}\text { Median lethal } \\
\text { time (d) }\end{array}$} & \multicolumn{2}{|c|}{$95 \%$ confidence limits } \\
\hline & & Lower & Upper \\
\hline \multicolumn{4}{|l|}{ Acartia tonsa } \\
\hline \multicolumn{4}{|l|}{23 Jun 1993} \\
\hline Anoxia & 28.95 & - & - \\
\hline Sulfide & 9.46 & 7.64 & 11.14 \\
\hline \multicolumn{4}{|l|}{$13 \mathrm{Jul} 1993$} \\
\hline Anoxia & 7.51 & 6.88 & 8.15 \\
\hline Sulfide & 8.98 & 7.85 & 10.02 \\
\hline \multicolumn{4}{|c|}{ Centropages hamatus } \\
\hline \multicolumn{4}{|c|}{$3 \operatorname{Jan} 1994$} \\
\hline Anoxia & 16.86 & 12.23 & 23.46 \\
\hline Sulfide & 11.77 & 8.43 & 15.12 \\
\hline \multicolumn{4}{|l|}{31 Jan 1994} \\
\hline Anoxia & $>32.00$ & - & - \\
\hline Sulfide & 8.73 & 4.98 & 11.89 \\
\hline \multirow{2}{*}{\multicolumn{4}{|c|}{ Labidocera aestiva }} \\
\hline 26 Jul 1993 & & & \\
\hline Anoxia & $>32.00$ & - & - \\
\hline Sulfide & $>32.00$ & - & $\sim$ \\
\hline \multicolumn{4}{|l|}{8 Aug 1993} \\
\hline Anoxia & 4.98 & 1.96 & 7.23 \\
\hline Sulfide & 0.39 & - & - \\
\hline
\end{tabular}


were judged to be non-viable and not diapause. The differences in egg viability observed in the experiments conducted with the same species, but at different times of the year, may have been due to differences in the genetic and/or environmental histories of the females used to obtain eggs. Because of these potential differences it is valid to compare the results obtained for anoxia and sulfide in each experiment, but not between experiments. These results were consistent in not showing any significant difference in viability for eggs exposed to sulfide compared to anoxia alone. Although the decline in egg viability of each species differed for the experiments conducted on different days, the results are generally within the range of values reported by Marcus \& Lutz (1994).

Although many eggs died within 2 to $4 \mathrm{wk}$ when exposed to anoxia, the fact that some eggs were able to survive for days to weeks indicates that they probably switched to anaerobic motabolism. Facultative anaerom biosis is typical of many invertebrates that are exposed to hypoxia or anoxia (see Hand 1991). The differences in survival that were observed among eggs within each species may have been due to differences in the amount of stored energy, whereas the differences in survival of eggs among the 3 species may have been due to differences in the experimental incubation temperatures, degree of metabolic rate depression, and amount of stored energy. Survival is typically greater at colder temperatures (e.g. Theede et al. 1969), and many species undergo metabolic rate depression to conserve energy (Storey 1988). Since initial oxygen concentrations in many of the vials ranged between 0.00 to $0.01 \mathrm{ml} \mathrm{I}^{-1}$ and final oxygen concentrations in 5 vials ranged from 0.01 to $0.03 \mathrm{ml} \mathrm{l}^{-1}$, it is possible that eggs continued to respire aerobically, though at a much reduced rate. However, further support for facultative anaerobiosis is evident from the response of eggs to sulfide. The presence of sulfide demands an absence of oxygen, suggesting that the eggs which survived exposure to sulfide must have switched to anaerobic respiration. Since the primary targets of sulfide are aerobic respiratory enzymes, e.g. cytochrome $c$ oxidase, eggs may gain protection from sulfide by undergoing anaerobic respiration, as is the case for other animals (e.g. Vismann 1991, Oeschger \& Storey 1993).

Total sulfide is represented in seawater by hydrogen sulfide $\left(\mathrm{H}_{2} \mathrm{~S}\right)$, bisulfide ( $\left.\mathrm{HS}^{-}\right)$and the sulfide ion $\left(\mathrm{S}^{-2}\right)$. Hydrogen sulfide is regarded as the most toxic form of sulfide (National Research Council 1979). The concentration of the different sulfide forms is dependent upon $\mathrm{pH}$. Between 5 and $25^{\circ} \mathrm{C}$ and at a $\mathrm{pH}$ of 8.1 , less than $10 \%$ of the total sulfide in seawater $(34 \%)$ is represented by $\mathrm{H}_{2} \mathrm{~S}$ (Goldhaber \& Kaplan 1975). At a pH of 7.0, approximately $50 \%$ of the total sulfide is represented by $\mathrm{H}_{2} \mathrm{~S}$. In the field, $\mathrm{pH}$ values of sediment pore- water generally range from 6.9 to 8.3 (Ben-Yaakov 1973). We conducted our sulfide experiments at $\mathrm{pH}$ levels ranging from 8.11 to 8.67 to be able to compare the results to our previous studies on the effects of anoxia (Marcus \& Lutz 1994). Thus, it is possible that sulfide levels similar to the concentrations which we tested would be more harmful to eggs at a $\mathrm{pH}$ closer to 7 .

The capacity of subitaneous copepod eggs to survive exposure to anoxia and sulfide for $8 \mathrm{~d}$ and in some cases $>32 d$ is comparable to the survival capacity of non-crustacean benthic fauna that dwell in anoxic and sulfide rich environments (e.g. Theede et al. 1969, Fox \& Powell 1987, Oeschger 1990, Vismann 1990). Our study indicates that early stage subitaneous copepod embryos which sink to the sea bed can survive days to weeks in the sediments, but year-to-year survival is doubtful. Moreover, increases in the duration and spatial coverage of water column anoxia in coastal waters should reduce hatching and thus adversely affect the population dynamics of these organisms.

Acknowledgements. We thank F. Chen, L. Stalder, and C. E Wiese for their assistance in the laboratory and J. Stein for statistical advice. Work supported by NSF Grant OCE-9202322 to N.H.M. and J.P.C. Publication No 1090 of the Florida State University Marine Laboratory.

\section{LITERATURE CITED}

Bagarinao T (1992) Sulfide as an environmental factor and toxicant: tolerance and adaptation in aquatic organisms. Aquat Toxicol 24:21-62

Ban S, Minoda T (1992) Hatching of diapause eggs of Eurytemora affinis (Copepoda:Calanoida) collected from lakebottom sediments. J Crustacean Biol 12:51-56

Ben-Yaakov S (1973) pH buffering of pore water of recent anoxic sediments. Limnol Oceanogr 18:86-94

Cline JD (1969) Spectrophotometric determination of hydrogen sulfide in natural waters. Limnol Oceanogr 14:454-458

Fenchel TM, Riedl R (1970) The sulfide system: a new biotic community underneath the oxidized layer of marine sand bottoms. Mar Biol 7:255-268

Finney DJ (1952) Probit analysis. Cambridge University Press Cambridge

Fox CA, Powell EN (1987) The effect of oxygen and sulfide on $\mathrm{CO}_{2}$ production by three acoel turbellarians. Are thiobiotic meiofauna aerobic? Comp Biochem Physiol 86A:509-514

Goldhaber MB, Kaplan IR (1975) Apparent dissociation constants of hydrogen sulfide in chloride solutions. Mar Chem 3:83-104

Hand SC (1991) Metabolic dormancy in aquatic invertebrates. Adv Comp Environ Physiol 8:1-50

Lutz RV, Marcus NH, Chanton JP (1992) Effects of low oxygen concentrations on the hatching and viability of eggs of marine calanoid copepods. Mar Biol 114:241-247

Marcus NH (1996) Ecological and evolutionary aspects of dormancy in copepods. Past, present and future studies. Hydrobiologia 320:141-152

Marcus NH, Lutz RV (1994) Effects of anoxia on the vlability of subitaneous eggs of planktonic copepods. Mar Biol 121: $83-87$

Marcus NH, Lutz RV, Burnett W, Cable P (1994) Age, viabil- 
ity, and vertical distribution of zooplankton resting eggs from an anoxic basin: evidence of an egg bank. Limnol Oceanogr 39:154-158

National Research Council (1979) Hydrogen sulfide. University Park Press, Baltimore

Oeschger R (1990) Long-term anaerobiosis in sublittoral marine invertebrates from the Western Baltic Sea: Hallcryptus spinulosus (Priapulida), Astarte borealis and Arctica islandica (Bivalvia). Mar Ecol Prog Ser 59:133-143

Oeschger R, Storey KB (1993) Impact of anoxia and hydrogen sulfide on the metabolism of Arctica islandica L. (Bivalvia). J Exp Mar Biol Ecol 170:213-226

Revsbech NP, Jørgensen BB, Blackburn TH (1980a) Oxygen in the sea bottom measured with a microelectrode. Sciences NY 207:1355-1356

Revsbech NP, Sørensen J, Blackburn TH, Lomholt JP (1980b) Distribution of oxygen in marine sediments measured with microelectrodes. Limnol Oceanogr 25:403-411

This note was submitted to the editor
SPSS (1993) SPSS for Windows, Advanced Statistics, Release 6.0. SPSS Inc, Chicago

Storey KB (1988) Suspended animation: the molecular basis of metabolic rate depression. Can J Zool 66:124-132

Theede $\mathrm{H}$, Ponat A, Hiroki K, Schlieper C (1969) Studies on the resistance of marine bottom invertebrates to oxygendeficiency and hydrogen sulfide. Mar Biol 2:325-337

Uye S, Fleminger A (1976) Effects of various environmental factors on egg development of several species of Acartia in southern California. Mar Biol 3:253-262

Uye S, Yoshiya M. Ueda K, Kasahara S (1985) The effect of organic sea-bottom pollution on survivability of resting eggs of neretic calanoids. Crustaceana 46:390-405

Vismann B (1990) Sulfide detoxification and tolerance in Nereis (Hediste) diversicolor and Nereis (Neanthes) virens (Annelida:Polychaeta). Mar Ecol Prog Ser 59:229-238

Vismann B (1991) Sulfide tolerance: physiological mechanisms and ecological implications. Ophelia 34:1-27

Manuscript first received: August 21, 1996

Revised version accepted: November 15, 1996 